\title{
Comment on "Simulation of Surface Ozone Pollution in the Central Gulf Coast Region Using WRF/Chem Model: Sensitivity to PBL and Land Surface Physics"
}

\author{
Jonathan E. Pleim \\ Atmospheric Modeling and Analysis Division, National Exposure Research Laboratory, USEPA, Research Triangle Park, \\ NC 27711, USA \\ Correspondence should be addressed to Jonathan E. Pleim, pleim.jon@epa.gov
}

Received 15 February 2011; Accepted 4 May 2011

Copyright (๑) 2011 Jonathan E. Pleim. This is an open access article distributed under the Creative Commons Attribution License, which permits unrestricted use, distribution, and reproduction in any medium, provided the original work is properly cited.

A recently published meteorology and air quality modeling study has several serious deficiencies deserving comment. The study uses the weather research and forecasting/chemistry (WRF/Chem) model to compare and evaluate boundary layer and land surface modeling options. The most serious of the study's deficiencies is reporting WRF/Chem results for both meteorological and chemical quantities using the asymmetric convective model version 2 (ACM2). While the ACM2 is a valid model option for WRF, it has not yet been implemented for the chemical portion of the WRF/Chem model. Hence, the reported air quality modeling results using ACM2 are invalid. Furthermore, publication of these results gives the erroneous impression that the ACM2 model is not well suited for air quality applications when, in fact, it is the default boundary layer model in the community multiscale air quality (CMAQ) model.

Yerramilli et al. [1] describe a modeling study using the weather research and forecasting/chemistry (WRF/Chem) model to study the sensitivity of meteorology and air quality modeling results to various combinations of planetary boundary layer (PBL) and land surface models (LSMs). This study has many deficiencies, including an inadequate spinup period from uniform initial chemical conditions $(12$ hours), fixed lateral chemical boundary conditions on an outer domain that is limited to a small region (the southeastern United States), and no information on soil moisture initialization which is crucial for good LSM performance. In addition, one of the PBL options used for their WRF/Chem model simulations was the asymmetric convective model version 2 (ACM2) $[2,3]$ which has not been implemented for use with the chemical part of the WRF/Chem model. Thus, the results shown for modeled $\mathrm{O}_{3}$ and $\mathrm{NO}_{2}$ concentrations using the ACM2 PBL scheme are invalid. WRF/Chem results using the ACM2 were compared to model simulations using the Yonsei University PBL model (YSU) [4] and the Mellor-Yamada-Janjic TKE model (MYJ) [5]. It was noted in the paper that "The patterns of ozone concentration from model runs with ACM PBL are drastically different to those from YSU and MYJ schemes and reveal localization of simulated Ozone." Given the very comparable results for meteorological variables (temperature, relative humidity, wind speed, and direction) among the three PBL models, it should have been obvious that ACM2 was not correctly implemented for chemistry. Therefore, I feel that it is important to correct the erroneous impressions given by Yerramilli et al. that the ACM2 model is ill suited for air quality modeling. Quite the contrary, the ACM2 model is unique among PBL models with nonlocal components (e.g., the YSU PBL model) to have completely consistent treatment of meteorological and chemical variables. For this reason, ACM2 is the default PBL scheme used in the community multiscale air quality (CMAQ) model [6].

The chemical vertical mixing module in WRF/Chem is a simple first-order closure scheme using the eddy diffusion coefficients for heat $\left(K_{h}\right)$ that are computed in the meteorological part of WRF. The ACM2 module in WRF, however, does not return the data array containing the eddy diffusion coefficient. Thus, WRF/Chem uses the minimum value set in 


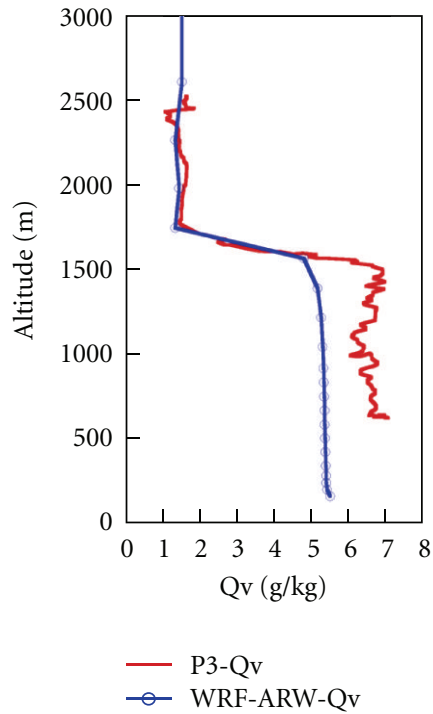

(a)

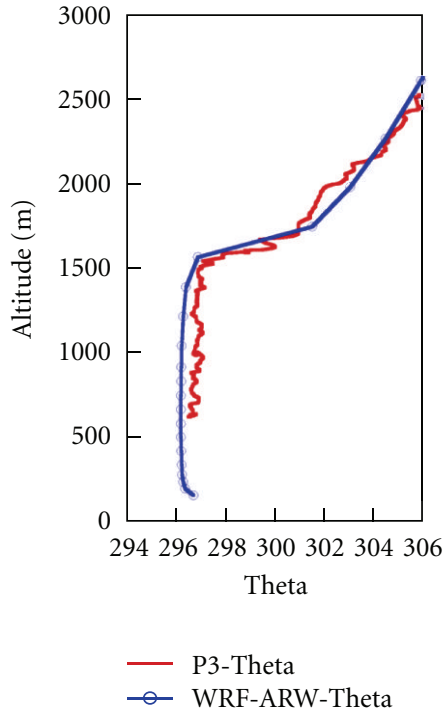

(b)

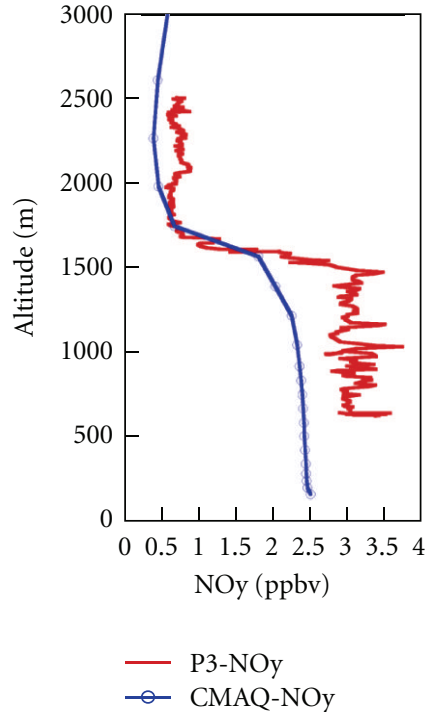

(c)

FIGURE 1: Comparisons of WRF and CMAQ model results compared to measurements from an NOAA WP-3D aircraft spiral on September 25,2006 at 19 UT.

the dry_dep_driver module for computing vertical diffusion of all chemical species. A global minimum value of $K_{h}$ is set to $10^{-6} \mathrm{~m}^{2} / \mathrm{s}$ with higher values for the lowest layers over land $\left(K_{h}=1.0 \mathrm{~m}^{2} / \mathrm{s}\right)$ and in areas of higher pollutant (CO) emissions $\left(K_{h}=2.0 \mathrm{~m}^{2} / \mathrm{s}\right)$. Hence, the WRF/Chem runs where ACM2 was selected used these minimum static values for $K_{h}$ resulting in ozone fields that are radically different from the runs using other PBL models as shown in Figure 11 of Yerramilli et al. [1]. Vertical diffusion of chemical species was grossly underrepresented by the runs using ACM2, especially during convective conditions, because the chemical scalars were essentially not being mixed in the vertical.

Note that by using the $K_{h}$ directly from the PBL scheme, the chemical part of WRF/Chem is limited to a local eddy diffusion representation of subgrid vertical transport. While this is consistent for local schemes such as the TKE models (e.g., MYJ), it is not consistent for PBL models with nonlocal components such as the YSU scheme. In addition to eddy diffusion, the YSU model represents transport by large convective eddies by means of a gradient adjustment term for heat and winds. The YSU scheme also has an explicit PBL top entrainment flux term [7]. Thus, the WRF/Chem implementation of YSU is inconsistent with the PBL processing of meteorological variables since it neglects these additional flux terms.

Like the YSU model, the ACM2 includes components for both local gradient diffusion and for nonlocal convective transport. Unlike the YSU model, however, the ACM2 treats nonlocal flux as a mass flux that is equally applicable to any atmospheric quantity, meteorological or chemical. Correct implementation of the ACM2 requires either complete integration for all quantities or duplicate implementations in meteorology and air quality models. Thus, ACM2 has been implemented in both WRF and CMAQ to provide identical PBL processing for meteorological and chemical constituents. For example, WRF and CMAQ, both using the ACM2 model, were run on identical model grids and compared to measurements from spiral flight paths by the NOAA WP-3D aircraft during the 2006 Texas Air Quality Study (TexAQS II) [8]. Figure 1 shows modeled and measured vertical profiles of water vapor mixing ratio $(\mathrm{Qv})$, potential temperature (Theta), and total reactive nitrogen (NOy). While Qv and NOy are both underpredicted by the model in the PBL the shape of the profiles and depth of the well-mixed layer are well modeled for all three parameters, demonstrating consistent and accurate PBL mixing for both meteorological and chemical constituents.

Several recent model evaluation studies have shown state-of-the-science performance for WRF simulations (e.g., $[9,10])$ and CMAQ simulations $[11,12]$ using ACM2. The ACM2 could be similarly implemented in WRF/Chem as in the WRF/CMAQ system. Because ACM2 was designed especially for air quality applications, it would be advantageous to the WRF/Chem community to have this capability. However, until this is done, ACM2 should not be used for WRF/Chem modeling, and results using this invalid model configuration should not have been published.

\section{Acknowledgment}

The United States Environmental Protection agency through its Office of Research and Development funded and managed the research described here. It has been subjected to agency review and approved for publication. 


\section{References}

[1] A. Yerramilli, V. S. Challa, V. B. R. Dodla et al., "Simulation of surface ozone pollution in the central gulf coast region using WRF/Chem model: sensitivity to PBL and Land surface physics," Advances in Meteorology, vol. 2010, Article ID 319138, 24 pages, 2010.

[2] J. E. Pleim, "A combined local and nonlocal closure model for the atmospheric boundary layer. Part I: model description and testing," Journal of Applied Meteorology and Climatology, vol. 46, no. 9, pp. 1383-1395, 2007.

[3] J. E. Pleim, "A combined local and nonlocal closure model for the atmospheric boundary layer. Part II: application and evaluation in a mesoscale meteorological model," Journal of Applied Meteorology and Climatology, vol. 46, no. 9, pp. 13961409, 2007.

[4] S.-Y. Hong, Y. Noh, and J. Dudhia, "A new vertical diffusion package with an explicit treatment of entrainment processes," Monthly Weather Review, vol. 134, no. 9, pp. 2318-2341, 2006.

[5] Z. I. Janjić, "Nonsingular implementation of the mellor yamada level 2.5 scheme in the NCEP meso model," Office Note No. 437, National Centers for Environmental Prediction, 2001.

[6] D. Byun and K. L. Schere, "Review of the governing equations, computational algorithms, and other components of the models-3 Community Multiscale Air Quality (CMAQ) modeling system," Applied Mechanics Reviews, vol. 59, no. 1-6, pp. 51-77, 2006.

[7] Y. Noh, W. G. Cheon, S.-Y. Hong, and S. Raasch, "Improvement of the K-profile model for the planetary boundary layer based on large eddy simulation data," Boundary-Layer Meteorology, vol. 107, no. 2, pp. 401-427, 2003.

[8] D. D. Parrish, D. T. Allen, T. S. Bates et al., "Overview of the second texas air quality study (TexAQS II) and the Gulf of Mexico atmospheric composition and climate study (GoMACCS)," Journal of Geophysical Research, vol. 114, no. 13, Article ID D00F13, 28 pages, 2009.

[9] R. C. Gilliam and J. E. Pleim, "An evaluation of the Pleim-Xiu land surface model, surface-layer and asymmetric convective model in version 3.0 of WRF ARW," Journal of Applied Meteorology and Climatology, vol. 49, pp. 760-774, 2010.

[10] J. E. Pleim and R. Gilliam, "An indirect data assimilation scheme for deep soil temperature in the Pleim-Xiu land surface model," Journal of Applied Meteorology and Climatology, vol. 48, no. 7, pp. 1362-1376, 2009.

[11] K. M. Foley, S. J. Roselle, K. W. Appel et al., "Incremental testing of the community multiscale air quality (CMAQ) modeling system version 4.7," Geoscientific Model Development, vol. 3, pp. 205-226, 2010.

[12] K. W. Appel, S. J. Roselle, R. C. Gilliam, and J. E. Pleim, "Sensitivity of the Community Multiscale Air Quality (CMAQ) Model v4.7 results for the eastern United States to MM5 and WRF meteorological drivers," Geoscientific Model Development, vol. 3, pp. 169-188, 2010. 

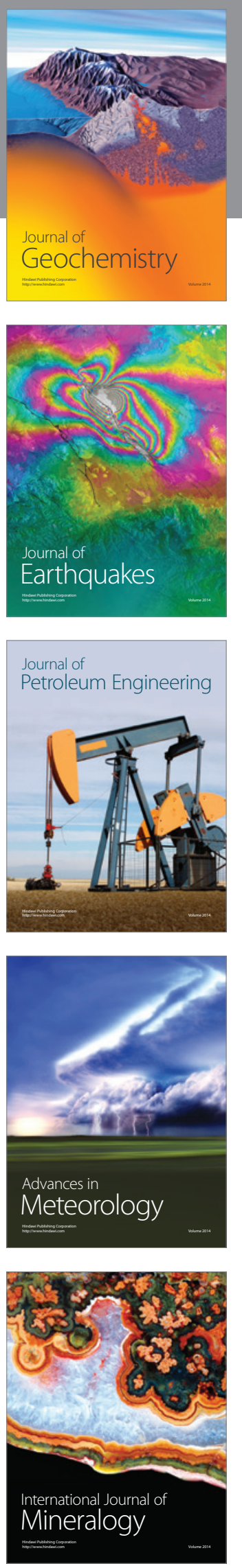
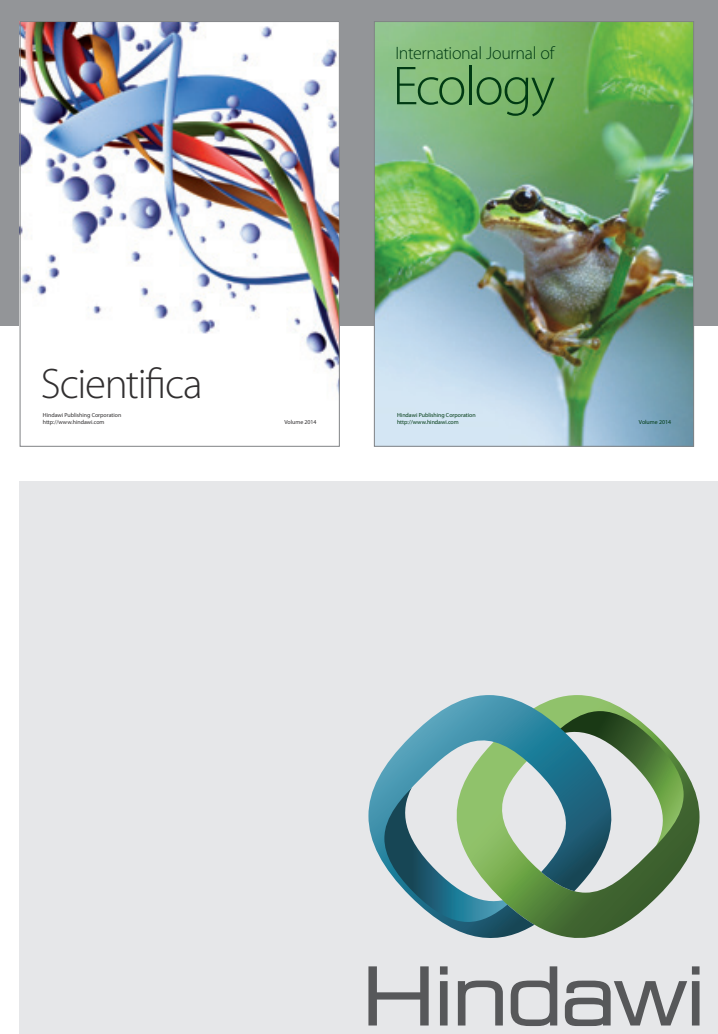

Submit your manuscripts at http://www.hindawi.com
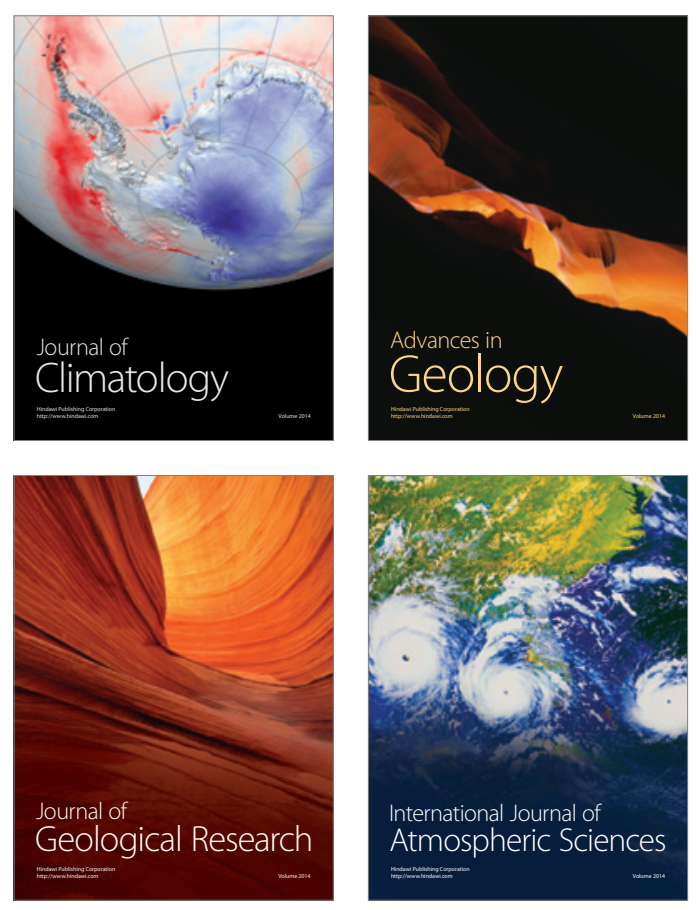
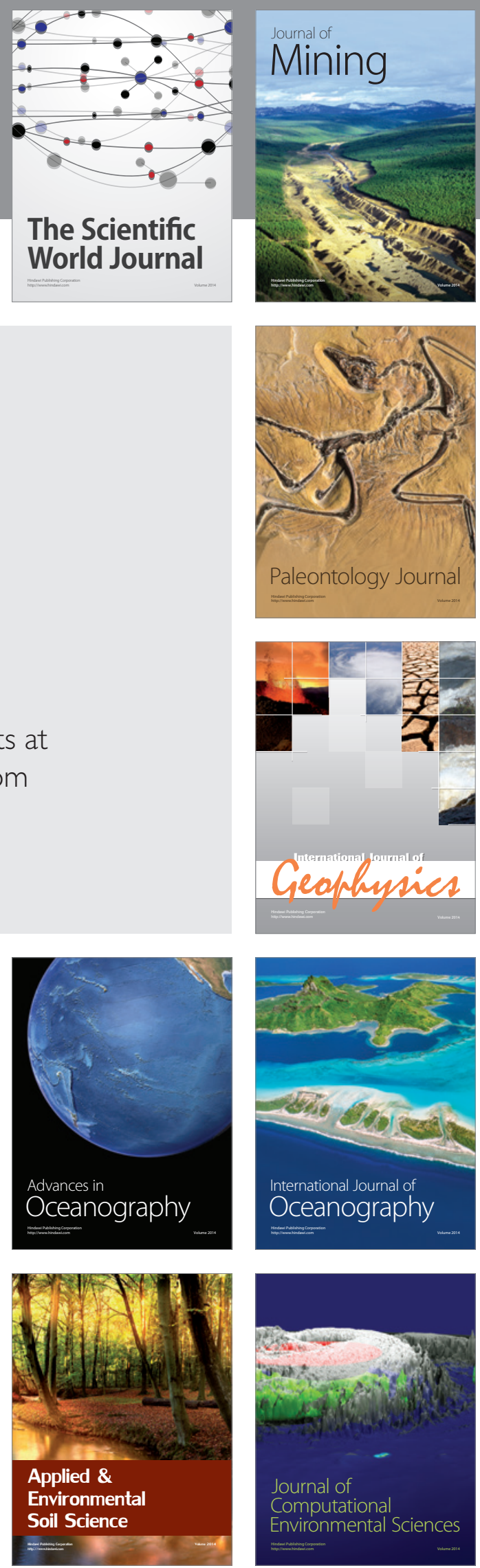